BULLETIN OF THE

AMERICAN MATHEMATICAL SOCIETY

Volume 79, Number 4, July 1973

\title{
THE NOVEMBER MEETING IN CLEVELAND
}

The seven hundredth meeting of the American Mathematical Society was held at Case Western Reserve University, Cleveland, Ohio, on Saturday, November 25, 1972. There were 149 registrants, including 111 members of the Society.

By invitation of the Committee to Select Hour Speakers for Western Sectional Meetings, there were two one-hour addresses. Professor Calvin R. Putnam of Purdue University addressed the Society on the subject Almost normal operators, their spectra and invariant subspaces; he was introduced by Professor Richard S. Varga. Professor Mary-Elizabeth Hamstrom of the University of Illinois at Urbana-Champaign spoke on the topic Homeomorphism and embedding spaces, PL and TOP; Professor Edward J. McShane presided at Professor Hamstrom's lecture.

By invitation of the same committee there were two special sessions of selected twenty-minute papers. Professor Lamberto Cesari of the University of Michigan arranged and chaired one such session on the subject of Optimization Theory and Optimal Control. The speakers were Lamberto Cesari, Henry G. Hermes, Edward J. McShane, and Roberto Triggiani ; in addition Professor Wendell $\mathrm{H}$. Fleming gave a brief tribute to the late Lucien W. Neustadt, who was originally scheduled to be one of the speakers in this session. The other special session was arranged by Professor Alan C. Woods of the Ohio State University on the subject of the Geometry of Numbers. The speakers were Peter W. Aitchison, Michael N. Bleicher, Thomas W. Cusick, Bohuslav B. Diviš, Lawrence C. Eggan, Richard B. Lakein, John M. Masley, Břetislav Novák, George B. Purdy, and Mushfequr Rahman; Professor Woods presided throughout.

There were five sessions of contributed ten-minute papers. These were chaired by Professor Simmie S. Blakney, Professor Arno Cronheim, Dr. John N. B. Livingood, Professor Leone Y. Low, and Dr. George B. Purdy. Of the 26 ten-minute papers listed in the program of the meeting, two were presented by title; one late paper was added to the program, so that 25 ten-minute papers were actually presented.

On Friday, November 24, 1972, the day before the meeting itself, Case Western Reserve University sponsored a symposium on the subject of Optimization Theory and Optimal Control. The speakers were Professors Thomas S. Angell, Wendell H. Fleming, Robert M. Goor, Marc Q. Jacobs, Rudolf E. Kalman, V. Jurdjevic, and Jack Warga. In addition Professor Cesari's special session on Saturday was an extension of this symposium. 